\title{
Rosales que florecen en el jardín en que se recrea el Divino Esposo: alegoría de una Religiosa
}

Rosebushes that bloom in the garden where the Divine Husband is recreated: allegory of a Religious

Claudia Cristell Marín Berttolini

Universidad Nacional Autónoma de México (claudia.marin.berttolini@gmail.com)

RESUMEN: La pieza en que se centra este análisis representa a una pequeña oveja que encarna en sí misma la identificación de las religiosas como parte del rebaño sagrado, guiado y protegido por el buen pastor, que habita en el jardín místico del espacio conventual en la promesa de la unión espiritual con Jesucristo. El detalle de la toca blanca y el velo negro remite a la oveja como una religiosa profesa; denotando un carácter de pertenencia a una comunidad conventual, cuya función transita entre lo alegórico, lo identitario y lo ceremonial. La presencia de esta alegoría en el espacio conventual se convierte en una oración mnemotécnica y artesanal llevada a cabo por la religiosa que al elaborar este tipo de piezas se afirmaba como parte del rebaño espiritual de Cristo.

PALABRAS CLAVE: Oveja, Buen Pastor, Alegoría, Labor de manos.

\begin{abstract}
This analysis focuses on an allegory of the nuns as part of the sacred herd and protected by the Good Shepherd; it represents a small sheep with white wimple and black veil, referring to a professed nun, living in the mystical garden of the convent in the promise of the spiritual union with Jesus Christ. With a function that transits among an allegorical, identity and ceremonial status, the presence of the sheep in the convent becomes a mnemotechnical and craft prayer made by the nun who would affirm her belonging to the spiritual herd of Christ when creating this kind of objects.
\end{abstract}

KEYWORDS: Sheep, Good Shepherd, Allegory, Craft Prayer.

De las diferentes alegorías que Jesucristo utilizó para predicar a sus discípulos, en las cuales afirmaba su labor mesiánica y la promesa de salvación, "yo soy el cordero", "yo soy la puerta”, "yo soy el camino", "yo soy la luz", "yo soy el pan"; destaca la figura del Buen Pastor, por un lado, debido a la 
gran cantidad de piezas que lo representan, así como por la vinculación que se efectuó entre Cristo como buen pastor y los apóstoles de los primeros años del cristianismo, y por ende, con san Pedro y la mitra episcopal; relación que detonó la redacción de diversos sermones, tratados y manuales de teología pastoral.

A esto se suma la tradición hebrea de la figura de autoridad personificada en el sumo sacerdote, que fungía las veces de pastor y conductor del rebaño, misma que en su momento fue encarnada por los grandes profetas y padres de la Iglesia como Abraham, Moisés o el mismo rey David (Foucault, 1990, pp. 99-101);1 por lo que se manifiesta la evocación directa a los textos sagrados, en los cuales la figura del cordero y el pastor habían estado presentes desde el Antiguo Testamento, desde el sacrificio de Isaac, hasta el Apocalipsis, en las visiones de san Juan Evangelista con el cordero sobre el libro de los siete sellos.

La peculiar pieza en que se centra este análisis representa a una pequeña oveja, que encarna en sí misma la identificación de las religiosas con el rebaño sagrado, guiado y protegido por el buen pastor, que habita en el jardín místico del espacio conventual en la promesa de la unión espiritual con Jesús Cristo, Jesús Pastor. El detalle de la toca blanca y el velo negro remite a la oveja como una religiosa profesa $[\mathbf{1}]_{2}$.

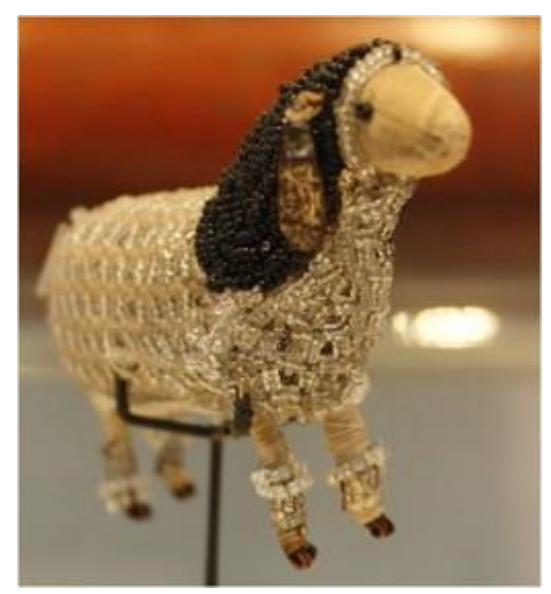

[Fig.1] Ovejita (¿Siglo XIX? ). Chaquiras o abalorios de cristal blanco y negro, alambre, papel metálico, hilo de seda y de algodón. 5 x $2.5 \mathrm{~cm}$. Museo de Arte Religioso Ex Convento de Santa Mónica

\footnotetext{
${ }^{1}$ Esta idea o concepto de la modalidad pastoral del poder está presente desde las sociedades orientales antiguas como Egipto, en donde el faraón porta un cayado de pastor como atributo de poder; Asiria, donde la asociación Rey-Dios se vincula con la función de cuidar las criaturas del gran pastor; hasta llegar a los hebreos, donde Dios es el pastor de su pueblo, lo agrupa, guía y conduce, asegura su salvación.

${ }^{2}$ Este estudio es resultado del trabajo del Seminario RECONOCER, coordinado por el Museo de Arte Religioso Ex Convento de Santa Mónica y la Benemérita Universidad Autónoma de Puebla, que forma parte del Programa de Investigación Especializada de la Colección del Museo de Santa Mónica, presentado el viernes 7 de julio de 2017.
} 


\section{Rebaño espiritual: Rosales que florecen en el jardín místico}

Esta pieza, que forma parte de la colección permanente del Museo de Arte Religioso Ex Convento de Santa Mónica en la ciudad de Puebla, es una figura de reducidas dimensiones, que forma parte del conjunto de labores manuales elaboradas por las religiosas como parte de su vida común. La pequeña oveja mide 5 centímetros de alto por 2.5 de ancho y fue creada con diferentes materiales; la estructura que le da sostén fue elaborada a base de alambre, el relleno probablemente sea hilo de algodón, que posteriormente fue recubierto con un textil tipo seda y finalmente, guarnecido por una trama de chaquiras o abalorios de cristal transparente y negro.

Se observan dos técnicas y materiales distintos en el trabajo de la chaquira. El cuerpo de la oveja está conformado por cuentas transparentes de mayor tamaño, formando un tejido en red que cubre casi toda la superficie. La sección de la toca es una hilera de chaquiras transparentes de menor tamaño, llamadas mostacillas o chinitas, por su origen vinculado al Galeón de Manila; al igual que la toca, que contrasta por el uso de cuentas de color negro, donde se observa igualmente la técnica de hileras cosidas a la superficie. En las patas se observa la aplicación hilo de seda y un fragmento de lámina de estaño recubierto por un alambre muy delgado y una hilera de chinitas transparentes. (Castelló, 1998, pp. 19,22, 35-39)

Sobresale de entre las demás piezas de la sala Ora et Labora por su singularidad y filiación alegórica. Estas labores de manos eran elaboradas por las religiosas con diferentes propósitos, para ayudar al sostenimiento económico del convento, como los encajes, bordados, esculturas y pinturas de pequeño formato; para obsequiar a sus bienhechores o familiares, o como objetos de uso ceremonial, como las coronas y palmas de profesión o los vestidos de niño Dios. Podían tener un carácter devocional, como los relicarios y pequeños altares decorados para alguna imagen; sin embargo, esta pieza denota un carácter de pertenencia a una comunidad o corporación, por lo que bien podría clasificarse como una representación de identidad corporativa, a través de la cual la religiosa se asume como parte del rebaño de Cristo, el buen pastor, esposo espiritual que contempla y resguarda eljardín místico donde viven sus ovejas3.

La pequeña oveja es una alegoría de la religiosa que entrega su vida a Cristo en una relación de amor ágape o caritas, entendido como una vinculación o mediación entre el hombre y Dios, que

\footnotetext{
${ }^{3}$ Destaca la existencia de varios costureros o cajas de labor como parte de los bienes muebles en resguardo en el Museo; algunos de ellos aún contienen materiales utilizados por las religiosas para elaborar dechados, flores y figuras para las coronas y palmas de profesión u objetos como esta oveja; uno de ellos contiene abalorios de diferentes colores y tamaños y otros dos tienen piezas elaboradas con dicho material que quedaron en proceso de armado, probablemente para hacer flores, que están elaboradas con la misma técnica de tejido en red. (Consulta personal a los depósitos, Junio 2017)
} 
tiene un origen divino e indica la gracia otorgada por el creador; misma que a partir de su autoconocimiento y del descubrimiento de Dios a partir de la evasión del siglo, del repudio a lo mundano y el retiro a su propio interior, ha dejado de pertenecer al mundo para ser sólo de Cristo, de tal modo que éste se convierte en la esencia de su corazón (Arendt, 2001, pp. 40-41, 44, 49, 61).

Así, al identificarse como una oveja que forma parte del rebaño celestial, la religiosa se adhiere a la promesa de una beata vita coram Deo (Arendt, 2001, pp. 31-32, 143), una vida feliz de cara a Dios. Esta afirmación se entiende como parte de un proceso de objetivación con base en el concepto de tecnologías del yo acuñado por Michel Foucault, entendidas como las técnicas que permiten a los individuos efectuar, por cuenta propia, o con la ayuda de otros, cierto número de operaciones sobre su cuerpo y su alma, pensamientos, conducta, o cualquier forma de ser, obteniendo así cuna transformación de sí mismos con el fin de alcanzar cierto estado de felicidad, pureza, sabiduría o inmortalidad (Foucault, 1990, pp. 35-36, 48). De este modo, la religiosa se observa, reconoce y transforma, para alcanzar dicho estado de felicidad, pureza e inmortalidad en Cristo.

En el pensamiento cristiano existen dos formas de descubrimiento de sí mismo, la exomologesis, que consiste en reconocerse como penitente en un estado constante de renuncia a sí mismo, en la búsqueda de la misericordia divina; y la exagoreusis, comprendida en la obediencia y la contemplación, características intrínsecamente vinculadas con la vida monástica, en que la religiosa debe cerciorarse de que su corazón se halla lo suficientemente puro como para ver a Dios (Foucault, 1990, pp. 83-85, 87-88).

Si bien ambas prácticas son distintas dado que la primera tiene un matiz corporal, performativo y teatral, mientras que la segunda tiene un carácter más interno y verbal; ambas se encuentran presentes en la afirmación de la pieza que estudiamos. La religiosa penitente que renuncia al siglo y a sí misma, se asume como parte de un cuerpo colectivo, el rebaño. Adquiere una identidad corporativa que le requiere el cumplimiento de determinadas normas, constituidas por la regla conventual, que le permitan alcanzar un estado de gracia que le mantengan en la constante presencia de su amado, Cristo, en el jardín conventual, donde idílicamente existe un estado de felicidad plena. Así, Cristo ejerce la función del Buen Pastor y cada una de las religiosas recibe de él una bondad constante e individualizada.

En los textos de teología pastoral, como Idea del Buen Pastor, de Francisco Núñez de Cepeda, se refiere a los conventos de vírgenes como rosales que florecen en el jardín cerrado de la Iglesia; los jardines en que se recrea el divino esposo, como en campo floreciente de azucenas; indicando al 
prelado que debe asistir a sus necesidades para poder cuidar de su encerramiento, que la belleza de sus flores (por la mayor parte), pende de su clausura (Núñez, 1682, pp. 541, 556).

Entre los diversos nombres y alegorías que se han elaborado de la figura de la religiosa y la vida conventual4, destaca la carta pastoral que Miguel Anselmo Álvarez de Abreu y Valdés, obispo de Antequera de Oaxaca, envía a las religiosas concepcionistas de dicho obispado, en la que retoma a san Francisco de Sales diciendo:

\begin{abstract}
“Muy amadas hijas, por cuanto más dichosas tengo las abejillas, que no salen de su colmena sino por el tiempo de la cosecha de la miel; y no se acompañan sino por componerla, y no tienen solicitud alguna sino por ella, donde el cuidado es ordenado y no hacen dentro de sus casas y monasterios sino la labor olorosa de la miel, y de la cera. Cuanto más dichosas son que estas avispas y moscones libertinos, que corriendo tan bajamente, y más por su voluntad a las cosas inmundas más que a las honestas, parece que no viven sino para importunar y dar pesadumbre al resto de los demás animales, por todo andan buscando, chupando, y picando mientras dura el estío y el otoño, y llegado el invierno se hallan sin albergue, sin provisión y sin vida. Cuando nuestras castas abejitas que no tienen por objeto de su vista, de su olfato y gusto sino la hermosura, la suavidad y la dulzura de las flores ordenadas a su intento, fuera de la nobleza de su ejercicio tienen un amable retiro, una provisión muy agradable, y una vida contenta en la abundancia de su antecedente trabajo" (Álvarez, 1770, pp. 26-27).
\end{abstract}

Volviendo a nuestro objeto de estudio, la imagen de la oveja transita entre lo corporativo y lo devocional, además de que encuentra eco en otras piezas de la colección del Museo de Arte Religioso Ex Convento de Santa Mónica, dado que aparece representada en dos pinturas, la primera vinculada con una devoción particular, San José de la Luz (1763), donde las ovejas con velo blanco y negro, representando religiosas novicias y profesas respectivamente, se identifican como el rebaño que sigue a su pastor y se vinculan devocionalmente pidiendo la intercesión del santo para la obtención de la gracia [2].

En otra pintura, la Alegoría del Dulcísimo Esposo (siglo XVIII), inspirada en el Cantar de los Cantares; se observa cómo Cristo guía y corteja al alma humana en el contexto del jardín místico, el cual se encuentra lleno de representaciones de flora y fauna, entre las cuales destaca una vez más la presencia de las ovejas con velo blanco y negro, las ovejas que el Buen Pastor mantiene a salvo en su

\footnotetext{
${ }^{4}$ Entre otras alegorías poéticas, destaca en el mismo contexto angelopolitano el obispo Domingo Pantaleón Álvarez de Abreu, quien refería a las religiosas dominicas como "rosas de mi corazón", basado en el texto de un Breviario Romano (Romero, s.f., p. 12); por otro lado, San Jerónimo retoma a Los Setenta llamándolas “dardos de Dios” (Jerónimo, 2003, pp. 222-223). Otros textos angelopolitanos, como la relación epistolar del obispo Manuel Fernández de Santa Cruz con diversas religiosas, las refiere como "súbditas"; mientras que el sermón del dominico Diego de Gorospe a la muerte del referido obispo las llama “doncellas virtuosas" (Bravo, 95, pp. 380-382).
} 
rebaño en un espacio terrestre-celeste-místico. Esta pintura fue estudiada por la doctora Patricia Díaz Cayeros para una exposición temporal en el mismo Museo, denominada Jardines Místicos: Huerto del celestial esposo y pensil eucarístico, inaugurada en mayo de 2013, identificándola como originaria del convento dominico de Santa Inés, formando parte de un mecanismo ceremonial y teatral, en el que la pieza constituía parte del repertorio visual del coro y se activaba doblándose y revelando la imagen del divino esposo. Las ovejas forman parte de la escena como copartícipes y protagonistas del gozo de la unión entre el alma humana y Cristo. [3]

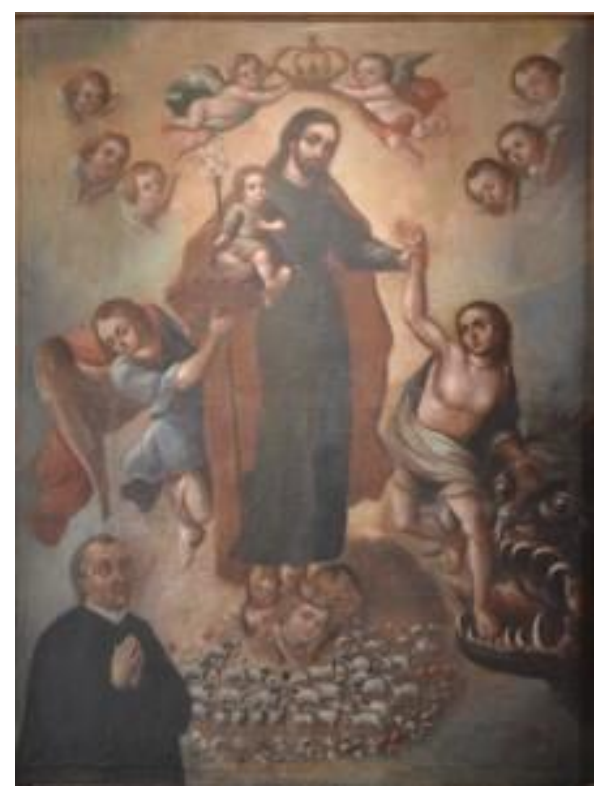

[Fig.2] Francisco Castillo -San José de la Luz (1763). Óleo sobre tela. Museo de Arte Religioso Ex Convento de Santa Mónica

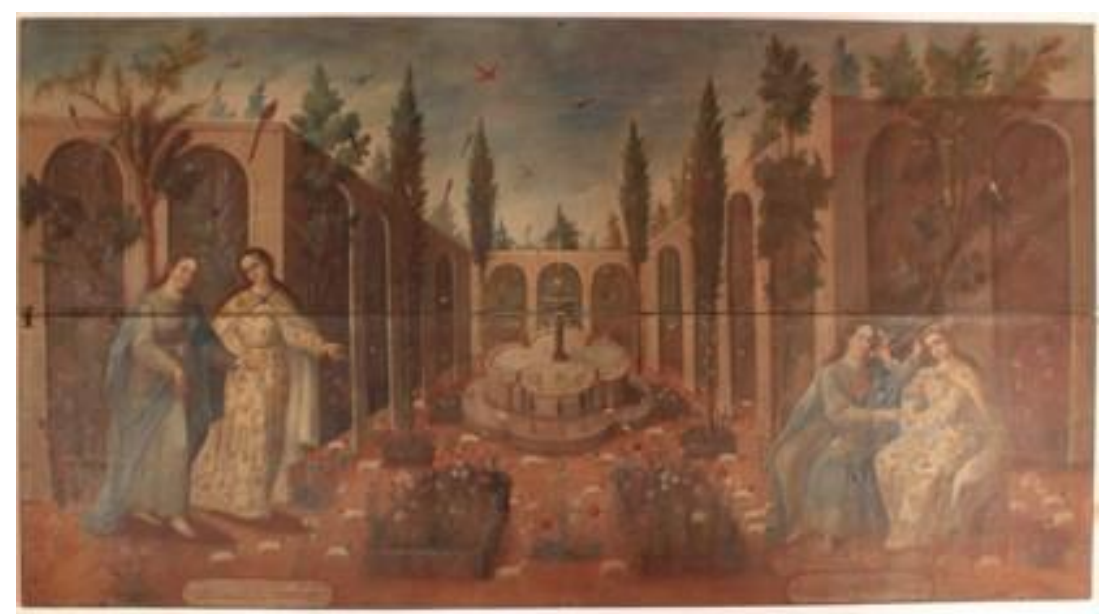

[Fig.3] Anónimo -Alegoría del jardín místico, Cantar de los Cantares o Jardín del Rey Salomón (S. XVIII) Óleo sobre tela. Museo de Arte Religioso Ex Convento de Santa Mónica 
Este punto nos lleva a la cuestión relativa a la filiación de la pieza. Debido a los colores que porta, tradicionalmente se le ha considerado como una pieza agustina; sin embargo hay que considerar que blanco y negro son colores que también utilizaron las órdenes dominicas y jerónimas en toca y velo, así como la existencia o evidencia de otras piezas similares en otras colecciones y en retratos de religiosas al momento de su profesión (Muriel, 1952, pp. 20-25).

Por un lado, tenemos la atribución original a las agustinas, que podría reforzarse con un pequeño detalle presente en la parte frontal del rostro de la oveja, en que se observa una cuenta de color negro, que tradicionalmente se ha vinculado con la espina o estigma de santa Rita de Casia, monja agustina que recibió de Cristo dicha herida en la frente y que la acompañó hasta su muerte. En algunos retratos de monjas agustinas se puede observar como al centro de la toca, éstas llevan una marca negra, en recuerdo y devoción a santa Rita de Casias .

Destaca también, en la misma ciudad de Puebla, la presencia en el Museo Bello y González de una pieza similar a la que estudiamos, pero que porta los colores azul y blanco, mismos que la identifican como originaria del convento de la Limpia Concepción de María, además del hecho de que en su confección se observa la presencia de perlas, lo que nos habla de las posibilidades económicas de las religiosas que en él profesaban. [4]

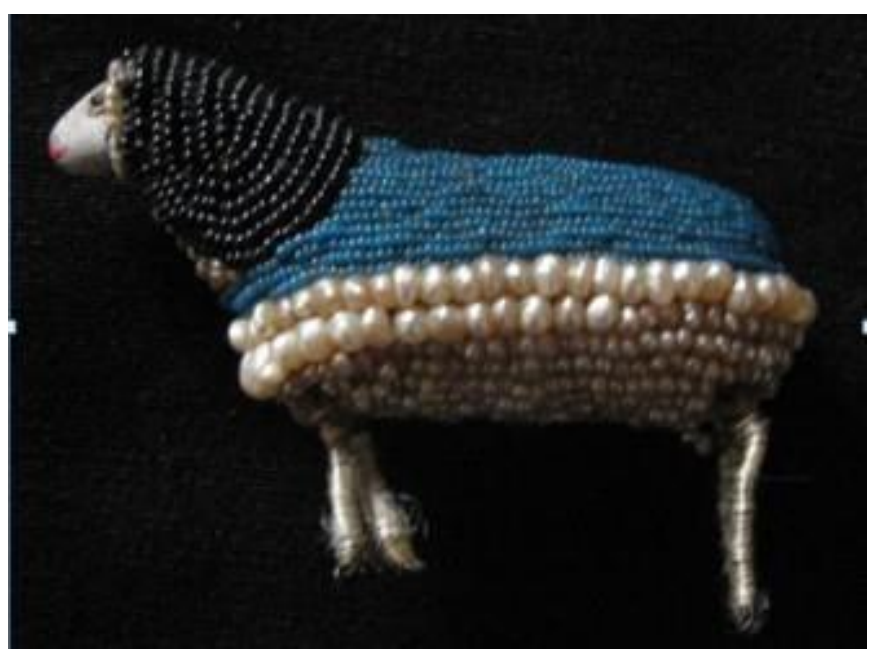

[Fig.4] Ovejita concepcionista (¿Siglo XIX?) Chaquiras o abalorios de cristal negro y azul, perlas de río, alambre, papel metálico, hilo de seda y de algodón. 5 x $2.5 \mathrm{~cm}$. Museo José Luis Bello y González

\footnotetext{
5 Hay además en el acervo del Museo diversos retratos del siglo XVIII que representan a monjas agustinas; e incluso algunos más contemporáneos, como el retrato de profesión de Sor María Guadalupe del Santísimo Sacramento, ya en formato fotográfico y fechado en 1896; así como otra fotografía de la comunidad agustina en el jardín del convento del siglo XX; todas ellas muestran a las religiosas con el detalle del estigma de santa Rita de Casia.
} 
Por otro lado, en el Museo Nacional de Historia Castillo de Chapultepec, se encuentra un retrato de profesión de una religiosa jerónima, fechado en 1769, de nombre María Francisca Josefa de san Felipe Neri, quien porta escapulario y capa roja, lo que la identifica como perteneciente al convento poblano de dicha orden. Dentro de los diferentes atributos o accesorios de profesión que ostenta, se puede observar la imagen del niño Jesús sobre un libro, en la cual aparece dos veces la imagen de la oveja, primero, junto al niño, elaborada con abalorios de colores negro y rojo, propios del hábito jerónimo, y posteriormente, otra pequeña oveja a sus pies, portando únicamente el velo negro. [5]

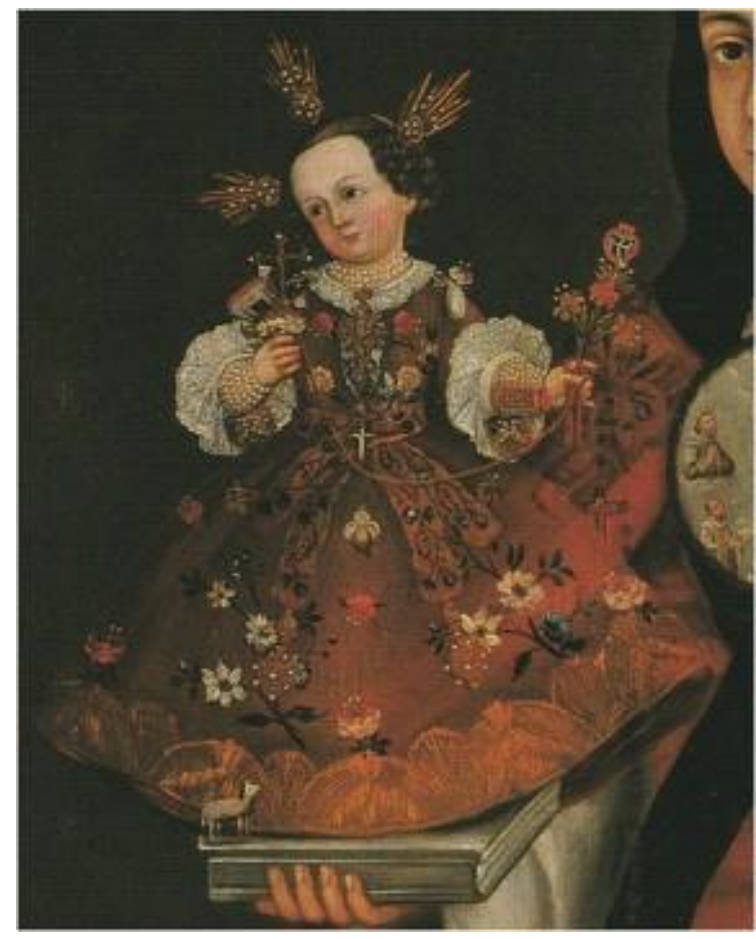

[Fig. 5] Anónimo -Retrato de Sor María Francisca Josefa de san Felipe Neri (detalle) (1769) Óleo sobre tela. Museo Nacional de Historia Castillo de Chapultepec

Por último, recordemos la presencia de las ovejas con velo negro y blanco en la Alegoría del Dulcísimo Esposo (siglo XVIII) del convento concepcionista de Santa Inés. Más allá de su pertenencia a un espacio conventual determinado, la existencia de estas piezas y su representación pictórica nos invita a reflexionar si la elaboración de las mismas fue una constante en las diferentes órdenes religiosas.

Según Jeffrey Hamburger, las imágenes realizadas por las monjas para las mismas monjas son, predominantemente, una afirmación de presencia, ellas desempeñaban un papel activo e ingenioso en la determinación de cómo se empleaban las imágenes en los rituales que dominaban su vida cotidiana. Describe los objetos como nuestra oveja como craft-prayer u oración artesanal, que testifica la manera 
en que estas piezas eran no sólo accesorios materiales, sino también recursos mnemotécnicos para la meditación. (Hamburger, 1998, pp. 17-18, 78)

Asimismo, Sor María de Ágreda, en su texto Mística Ciudad de Dios, al referirse en el Capítulo IV a la perfección con que la virgen María guardaba los preceptos y ceremonias del templo antes de desposarse con san José, refiere cómo de la hora tercia hasta la tarde, fue instruida por el sumo sacerdote a ocuparse en una labor de manos, "para en todo ser enseñada". Así, las religiosas, siguiendo el modelo de María, oraban y laboraban en el jardín conventual mientras sus manos creaban representaciones y objetos que afirmaban su identidad y presencia en el espacio místico del claustro (Ágreda, 1721, p. 364).

\section{Conclusiones}

Para nuestra pequeña oveja, su historia y función, su elaboración manual por parte de las religiosas, el significado y uso que tuvo para quien la poseía, nos remiten a la idea de retrato alegórico-corporativo, que identificaba a la religiosa como parte del rebaño conventual en la constante presencia de su amado, Cristo. Esta pieza ha traspasado su tiempo y momento, convirtiéndose en testigo de su historia y de las motivaciones de una religiosa que se representaba a sí misma en el objeto y afirmaba su entrega a Jesús con su elaboración. Su pervivencia como objeto cultural en el espacio del museo y en las representaciones pictóricas la han alejado del olvido, permitiéndonos encontrar en ella un espacio para la reflexión y la investigación de un corpus artístico que aún tiene muchas historias por contar.

\section{Recursos Bibliográficos}

ÁGREDA, Sor María de Jesús (1721). Mística Ciudad de Dios, Milagro de su omnipotencia y abismo de la gracia u Historia Divina y Vida de la Virgen Madre de Dios, Reyna y Señora nuestra María Santíssimma, Restauradora de la culpa de Eva y medianera de la Gracia, Imprenta de la causa de la Venerable Madre: Madrid.

ÁLVAREZ DE ABREU Y VALDÉS, Miguel Anselmo (1770). A las esposas de Jesu Christo nuestras amadas hijas las religiosas del convento de la Concepción de este nuestro obispado, salud y gracia, Oaxaca.

ARENDT, Hannah (2001). El concepto del amor en san Agustín, Ediciones Encuentro: Madrid. 
BRAVO ARRIAGA, María Dolores (1995), "Sermo autoritatis: Otras cartas del obispo Santa Cruz a monjas", Anuario Saber Novohispano (No. 2), 379-387. Recuperado de: http://www.iifilologicas.unam.mx/pnovohispano/uploads/95sabernovo/art25_95.pdf

CASTELló ITURBIDE, Teresa (1998). La chaquira en México, Artes de México: México.

FERNÁNDEZ FÉLIX, Miguel (2003). Monjas Coronadas, Museo Nacional del VirreinatoCONACULTA: México.

FOUCAULT, Michel (1990). Tecnologías del yo y otros textos afines, Ediciones Paidós Ibérica, S.A. y Universidad Autónoma de Barcelona: Barcelona.

HAMBURGER, Jeffrey (1998). The visual and the visionary. Art and female spirituality in late medieval Germany, Zone Books: New York.

MURIEL, Josefina (1952). Retratos de monjas, Editorial Jus: México.

NÚÑEZ DE CEPEDA, Francisco (1682). Idea del Buen Pastor, Imprenta de Anisson y Posuel: Madrid.

ROMERO, Joseph Valentín (s.f.), La más hermosa flor de las rosas, que aviendo amurallado su corazón en la primavera de su vida con las rosas de sus virtudes, esperamos renasca en el ibierno del sepulchro, como fragante rosa del verano, Puebla.

SAN JERÓNIMO (2003). Obras completas de san Jerónimo, Biblioteca de autores cristianos: Madrid. 